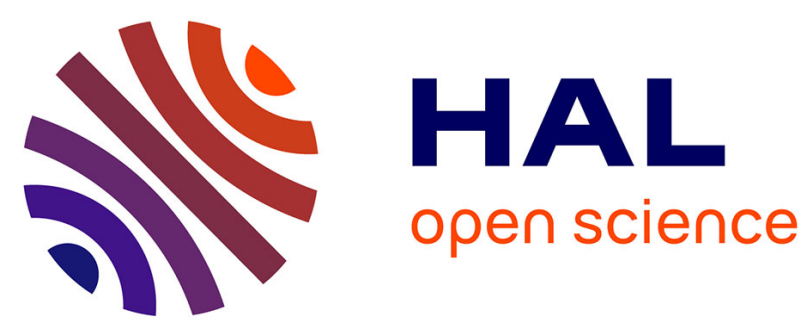

\title{
Global approach test improvement using a neural network model identification to characterise solar combisystem performances
}

Antoine Leconte, Gilbert Achard, Philippe Papillon

\section{To cite this version:}

Antoine Leconte, Gilbert Achard, Philippe Papillon. Global approach test improvement using a neural network model identification to characterise solar combisystem performances. Solar Energy, 2012, 86 (7), pp.2001-2016. 10.1016/j.solener.2012.04.003 • cea-02948533

HAL Id: cea-02948533

https://hal-cea.archives-ouvertes.fr/cea-02948533

Submitted on 24 Sep 2020

HAL is a multi-disciplinary open access archive for the deposit and dissemination of scientific research documents, whether they are published or not. The documents may come from teaching and research institutions in France or abroad, or from public or private research centers.
L'archive ouverte pluridisciplinaire HAL, est destinée au dépôt et à la diffusion de documents scientifiques de niveau recherche, publiés ou non, émanant des établissements d'enseignement et de recherche français ou étrangers, des laboratoires publics ou privés. 


\title{
Global approach test improvement using a neural network model identification to characterise solar combisystem performances
}

\author{
Antoine Leconte $^{\mathrm{a}, \mathrm{b}, *}$, Gilbert Achard ${ }^{\mathrm{a}}$, Philippe Papillon ${ }^{\mathrm{b}}$ \\ a LOCIE, CNRS FRE3220, Université de Savoie, Polytech'Annecy-Chambery, 73376 Le Bourget du Lac, France \\ ${ }^{\mathrm{b}}$ CEA LITEN INES, BP 332, 50 avenue du Lac Léman, 73377 Le Bourget du Lac, France
}

Received 7 April 2011; received in revised form 9 March 2012; accepted 8 April 2012

Available online 4 May 2012

Communicated by: Associate Editor C. Estrada-Gasca

\begin{abstract}
Solar CombiSystems (SCSs) are very efficient systems for reducing conventional energy consumption of building but their thermal performances are strongly dependent on the environment where they are installed (type of climate and thermal quality of the building). Currently it is impossible to predict the energy savings generated by a SCS as there is no standard test to characterise SCS performances.

Currently, the Short Cycle System Performance Test (SCSPT), based on a 12 days test of the complete SCS on a semi-virtual test bench, is able to predict annual energy savings with a good accuracy, but the performance prediction is limited to only one environment (the building and the climate corresponding with the test).

Based on the SCSPT procedure, this paper proposes an improvement of the method by identifying a global SCS model from the test data. Then, the identified model would be able to simulate the tested SCS in any environment and thus to characterise its performances.

The proposed model to identify is a "grey box" model, mixing a "White Box" model composed of known physical equations and a "Black Box" model, which is an Artificial Neural Network (ANN). A complete process is developed to train and select a relevant global SCS model from such a test.

This approach has been validated through numerical simulations of three detailed SCS models. Compared to those annual results, "Grey Box" SCS models trained from a twelve days sequence are able to predict energy consumption with a good accuracy for 27 different environments. An experimental application of this procedure has been used to characterise a real system.
\end{abstract}

(c) 2012 Elsevier Ltd. All rights reserved.

Keywords: Neural network; Solar combisystem; Performance prediction; Test bench; Characterisation

\section{Introduction}

Solar combisystems are complex solar thermal systems that provide energy for Domestic Hot Water (DHW) preparation and space heating. Solar energy and auxiliary

\footnotetext{
Abbreviations: ANN, Artificial Neural Network; CTSS, Component Testing - System Simulation; DHW, Domestic Hot Water; FSC, Fractional Solar Consumption; SCS, Solar CombiSystem; SCSPT, Short Cycle System Performance Test; SFH, Single Family House.

* Corresponding author at: INES RDI, 50 avenue du Lac Léman, 73377 Le Bourget du Lac, France. Tel.: +33 4794446 69; fax: +33 479621374. E-mail address: antoine.leconte@cea.fr (A. Leconte).
}

energy are managed in such a way that the thermal loads are covered to fulfil the comfort requirements of the user, but also to save as much as possible auxiliary energy. Each combisystem has its own feature concerning, for example, controller algorithm, hydraulic loops and storage design.

Nowadays, some combisystems can be very efficient and cover up to nearly $50 \%$ of the total heat demand with solar energy gains (Letz, 2006). However, such good results are met in very special cases because combisystem performances are very sensitive to climatic conditions and energetic quality of buildings. Besides, it is not unusual to see even poor design or installation mistakes making a 


\section{Nomenclature}

Variables and parameters in the collector model

$A_{\text {coll }} \quad$ collector area $\left(\mathrm{m}^{2}\right)$

$c_{1}$ heat loss coefficient at $\left(T_{\mathrm{m}}-T_{\mathrm{a}}\right)=0$ (W m ${ }^{-2} \mathrm{~K}^{-1}$ )

$c_{2}$ temperature dependence of the heat loss coefficient $\left(\mathrm{W} \mathrm{m} \mathrm{m}^{-2} \mathrm{~K}^{-2}\right.$ )

$c_{3} \quad$ wind speed dependence of the heat loss coefficient $\left(\mathrm{J} \mathrm{m}^{-3} \mathrm{~K}^{-1}\right)$

$c_{4} \quad$ sky temperature dependence of the heat loss coefficient $(-)$

$c_{5} \quad$ effective thermal capacity $\left(\mathrm{J} \mathrm{m}^{-2} \mathrm{~K}^{-1}\right)$

$c_{6} \quad$ wind dependence in the zero loss efficiency $\left(\mathrm{s} \mathrm{m}^{-1}\right)$

$E_{\mathrm{L}} \quad$ longwave irradiance $(\lambda>3 \mu \mathrm{m})\left(\mathrm{W} \mathrm{m}^{-2}\right)$

$F^{\prime} \quad$ collector efficiency factor $(-)$

$G$ total solar irradiance on the collector plane $\left(\mathrm{W} \mathrm{m}^{-2}\right.$ )

$G_{\mathrm{b}}$ beam solar irradiance on the collector plane $\left(\mathrm{W} \mathrm{m}^{-2}\right.$ )

$G_{\mathrm{d}} \quad$ diffuse solar irradiance on the collector plane $\left(\mathrm{W} \mathrm{m}^{-2}\right)$

$K_{\theta b} \quad$ incidence angle modifier $(-)$

$K_{\theta \mathrm{d}} \quad$ incidence angle modifier for diffuse radiation (-)

$\dot{Q}_{\text {coll }} \quad$ heat flow rate supplied by the collector (W)

$\dot{Q}_{\text {sol,net }}$ net solar energy available at the bounds of the collector $\left(\mathrm{W} \mathrm{m}^{-2}\right)$

$\dot{Q}_{\text {sol,ref }}$ reference solar irradiation (W)

$T_{\mathrm{a}} \quad$ ambient temperature $\left({ }^{\circ} \mathrm{C}\right)$

$T_{\text {coll }}$ mean temperature of the collector $\left({ }^{\circ} \mathrm{C}\right)$

$v \quad$ collector surrounding air speed $\left(\mathrm{ms}^{-1}\right)$

$\theta \quad$ angle of incidence $\left(^{\circ}\right)$

$\sigma \quad$ Stephan-Boltzman constant $\left(\mathrm{W} \mathrm{m}^{-2} \mathrm{~K}^{-4}\right)$

$(\tau \alpha)_{\mathrm{en}} \quad$ effective transmittance-absorptance product for direct solar radiation at normal incidence (-)

Variables and parameters in the radiator model

$C_{\mathrm{em}} \quad$ heat emitter effective heat capacity ( $\mathrm{W} \mathrm{h} \mathrm{K}^{-1}$ )

$K$ heat emitter characteristic coefficient ( $\mathrm{W} \mathrm{K}^{-n}$ )

$n \quad$ heat emitter characteristic exponent (-)

$\dot{Q}_{\text {em }} \quad$ heat flow rate supplied for the heat emitter (W)

$T_{\text {em }} \quad$ mean temperature of the heat emitter $\left({ }^{\circ} \mathrm{C}\right)$

Variables and parameters in the building model

$\dot{Q}_{\mathrm{d}} \quad$ standard heat load at design outdoor temperature for chosen location (W)

$T_{\mathrm{a}, \mathrm{d}} \quad$ ambient design temperature of heating system at chosen location $\left({ }^{\circ} \mathrm{C}\right)$

$T_{\text {room }}$ mean temperature of the room air $\left({ }^{\circ} \mathrm{C}\right)$

$T_{\text {set,room }}$ room setpoint temperature $\left({ }^{\circ} \mathrm{C}\right)$

Variables and parameters in the store model

$C_{\text {sto }} \quad$ storage tank effective heat capacity ( $\mathrm{W} \mathrm{h} \mathrm{K}^{-1}$ )

$\dot{Q}_{\text {aux,sto }}$ heat flow rate supplied by the auxiliary heater, at the bounds of the storage tank (W)
$\dot{Q}_{\text {dhw }} \quad$ heat flow rate supplied for the DHW demand (W)

$\dot{Q}_{\text {dhw,sto }}$ heat flow rate supplied for the DHW demand, at the bounds of the storage tank (W)

$\dot{Q}_{\text {coll,sto }}$ Heat flow rate supplied by the collector, at the bounds of the storage tank (W)

$\dot{Q}_{\text {em,sto }}$ heat flow rate supplied for the heat emitter, at the bounds of the storage tank (W)

$T_{\text {a,sto }}$ temperature of the air surrounding the storage $\left({ }^{\circ} \mathrm{C}\right)$

$T_{\text {tap }} \quad$ temperature of water at input of tap water net $\left({ }^{\circ} \mathrm{C}\right)$

$T_{\text {sto }} \quad$ mean temperature of the storage tank $\left({ }^{\circ} \mathrm{C}\right)$

$T_{\text {set,dhw }}$ DHW setpoint temperature $\left({ }^{\circ} \mathrm{C}\right)$

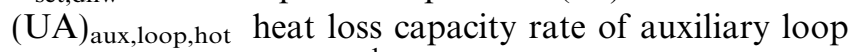
hot side $\left(\mathrm{W} \mathrm{K}^{-1}\right)$

(UA) aux,loop,cold heat loss capacity rate of auxiliary loop cold side $\left(\mathrm{W} \mathrm{K}^{-1}\right)$

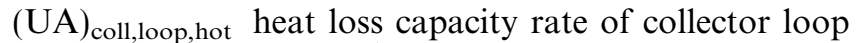
hot side $\left(\mathrm{W} \mathrm{K}^{-1}\right)$

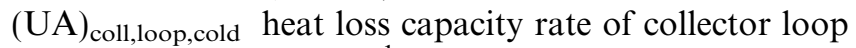
cold side $\left(\mathrm{W} \mathrm{K}^{-1}\right)$

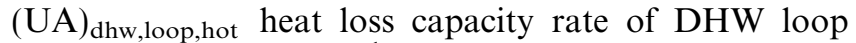
hot side $\left(\mathrm{W} \mathrm{K}^{-1}\right)$

(UA) $)_{\text {dhw,loop,cold }}$ heat loss capacity rate of DHW loop cold side $\left(\mathrm{W} \mathrm{K}^{-1}\right)$

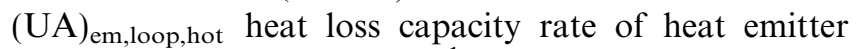
loop hot side $\left(\mathrm{W} \mathrm{K}^{-1}\right)$

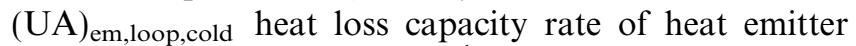
loop cold side $\left(\mathrm{W} \mathrm{K}^{-1}\right)$

$(\mathrm{UA})_{\text {sto }}$ heat loss capacity rate of the storage tank $\left(\mathrm{W} \mathrm{K}^{-1}\right)$

Variables and parameters in the auxiliary boiler model

$a_{\text {aux }} \quad$ boiler performance coefficient $\left(\mathrm{W}^{-1}\right)$

$b_{\text {aux }} \quad$ boiler performance coefficient $(-)$

$c_{\text {aux }}$ boiler performance coefficient (W)

$\dot{Q}_{\text {aux }} \quad$ power consumed by the auxiliary heater (W)

$\dot{Q}_{\text {aux }, \text { nom }}$ auxiliary heater nominal power (W)

$\dot{Q}_{\text {aux }, \text { out }}$ heat flow rate supplied by the auxiliary heater (W)

$T_{\text {set,boil }}$ set outlet temperature of auxiliary boiler $\left({ }^{\circ} \mathrm{C}\right)$

Symbols in system identification

$H \quad$ Heissian matrix of the cost function

$J \quad$ cost function

$N_{\mathrm{i}} \quad$ number inputs

$N_{\mathrm{n}} \quad$ number of neurones

$N_{\text {n,max }}$ maximum number of neurones

$N_{\mathrm{o}} \quad$ number of outputs

$N_{\text {tp }} \quad$ number of training patterns

$N_{\text {sw }} \quad$ number of synaptic weights

$u \quad$ input vector of system 
$w \quad$ synaptic weight

$x \quad$ state vector of system

$y \quad$ output vector of system $\tilde{y}$

$\mu \quad$ learning rate of the training algorithm

$v$ input of the activation function combisystem behave differently as it is supposed to (Thür, 2011). Performances can be reduced significantly in this way. Therefore, it would be important to have an idea of the performance expected before choosing a solar combisystem and installing it in a building.

Nevertheless, there is no test to characterise combisystems currently. Due to the large variety of energy management strategies and their sensitivity to external conditions, it is difficult to predict combisystem thermal performance in a reliable and complete way. Some test methods have been developed. They can be classified in two categories, depending on their approach to evaluate primary energy savings:

\subsection{Component approach}

Component approach method, like the "Component Testing - System Simulation" (CTSS) (Albaric et al., 2010; Drück and Bachmann, 2002), consists in testing the main components of solar combisystem (heat store, controllers, and collector) according to existing standard tests. Parameters of each component are identified and then used within thermal simulation software like TRNSYS (Klein et al., 1994).

This approach is very flexible as it is possible to test nearly every system configuration and to evaluate performances for different climatic conditions and different kinds of buildings, through several annual simulations.

On the other hand, it is not possible to check real system controls and interactions between components since they are only simulated. Design mistakes and installation difficulties can pass through this kind of test.

\subsection{Global approach}

Global approach method, like the "Annual Calculation and/or Direct Characterisation" (Bales, 2002), the "Concise Cycle Test" (Vogelsanger, 2002) and the "Short Cycle System Performance Test" (SCSPT) (Albaric et al., 2008), consists in testing each combisystem as a whole. The complete system is set up in an indoor test facility (except the collectors). Charging and discharging of the system are done according to a test sequence, peculiar to each method. For SCSPT method, the annual performance is derived from a simple extrapolation of the auxiliary energy consumed during the procedure.

This kind of approach ensures that all system functions and interactions are taken into account during the test. Furthermore, the time needed with this approach is quite short. The longer test sequence is 12 days long.

However, in this way, results are available to only one fixed set of conditions, according to the heating load, the climatic conditions and the system sizing (especially collector area) during the test.

The objective of the work presented in this paper is to further develop one of the global approach methods, the SCSPT. The improvement proposed here tries to get through the limitation of the global approach results in order to have a complete methodology to characterise combisystem thermal performance.

\section{The current SCSPT procedure}

The new methodology proposed in this paper is based on the SCSPT that has been developed at INES, the French National Institute for Solar Energy (Albaric et al., 2008, 2010). As a global approach method, the SCSPT first consists in installing the entire tested system on the semivirtual test bench.

\subsection{The semi-virtual test bench}

The semi-virtual test bench located in the INES facilities (Fig. 1) makes possible to test any thermal system or process, confronting it with a virtual environment. In the case of solar combisystem, all the components of the tested system (store(s), controller(s), pump(s), valve(s), sensor(s) and auxiliary energy device(s), if needed) are installed on the test bench as they are usually in a building. Weather variables, collectors, DHW draw-offs, heat emitter and building are simulated, in real time, within the TRNSYS software (Klein et al., 1994).

Communication between the real system and the virtual environment is done thanks to hydraulic modules. Modules are plugged in a hot water $\left(180^{\circ} \mathrm{C}\right)$ and a cold water

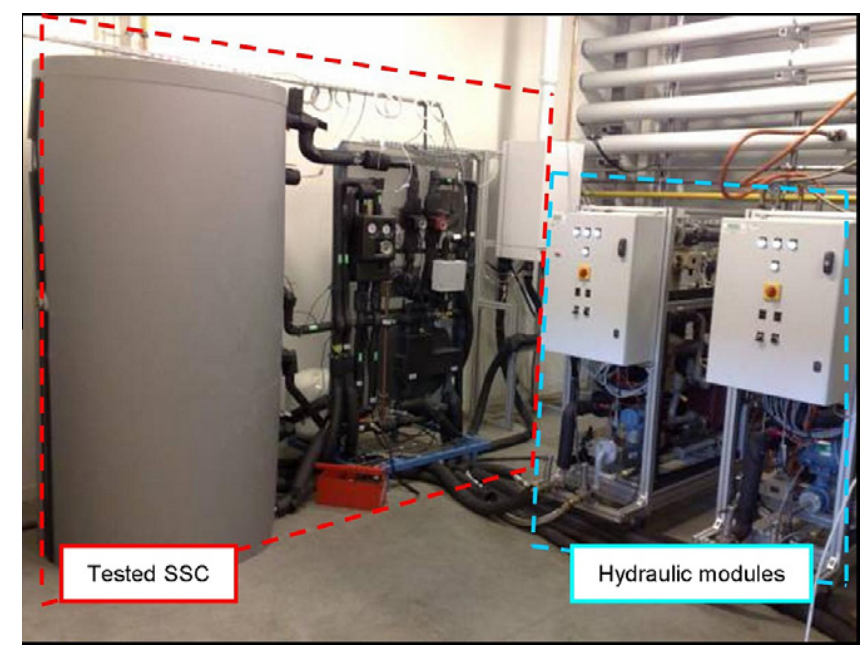

Fig. 1. Picture of a tested SCS on the semi-virtual test bench at INES 


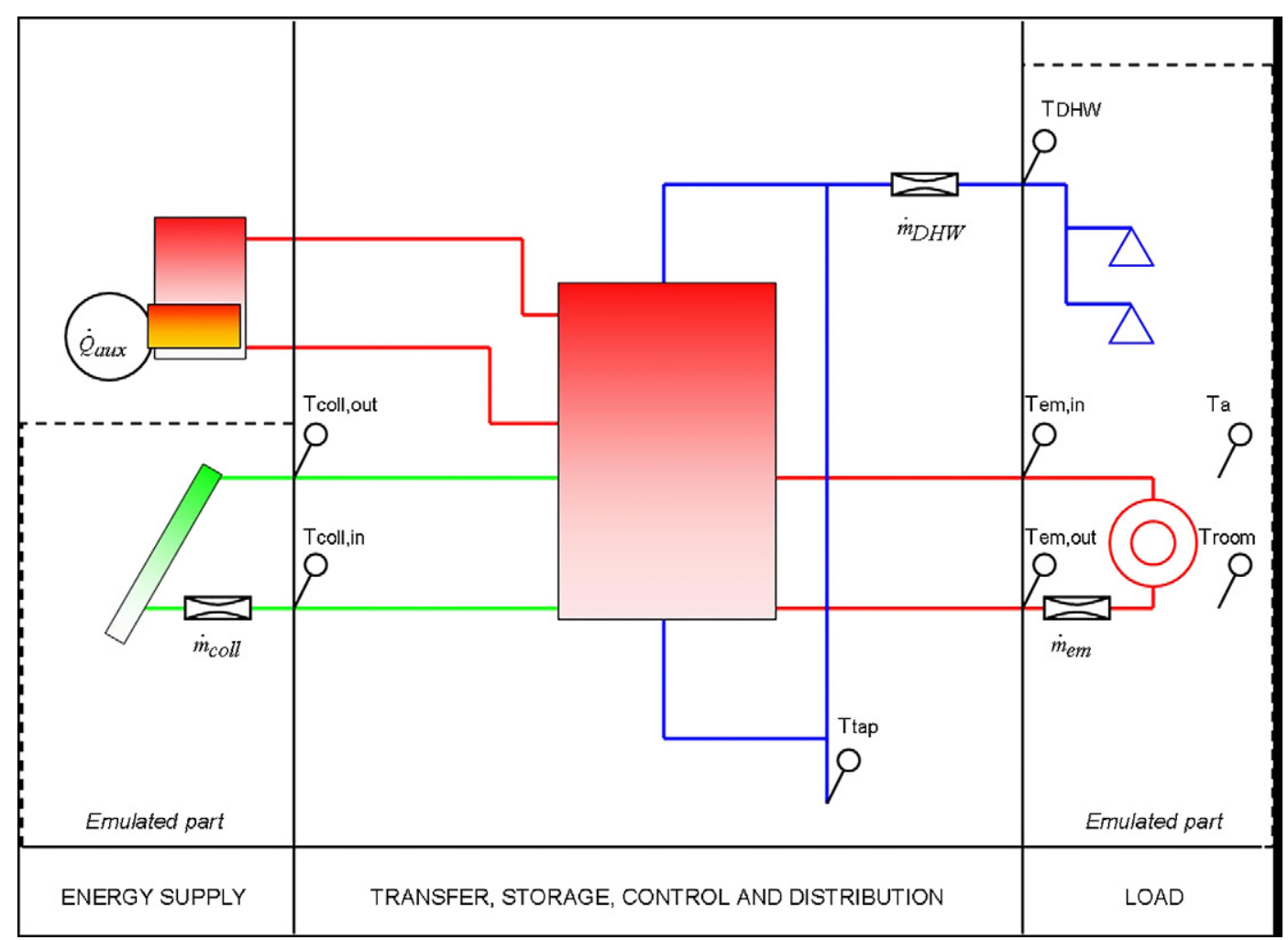

Fig. 2. Data recorded and exchanged between the real SCS and the emulated environment during a test on the semi-virtual test bench at INES.

$\left(-10^{\circ} \mathrm{C}\right)$ network, supplied by a central heating room. Thus, by means of heat exchangers, each module can produce or consume heat quickly from a secondary fluid when they are ordered to.

Each loop of the combisystem (mainly DHW, space heating and collector loops) is connected to a module. At every time step $(1 \mathrm{~min})$, modules record the temperature and the flow rate of incoming fluids and send these measurements to the monitoring computer. Those measurements are used as inputs to the TRNSYS simulation software. Then, according to the outputs of the TRNSYS calculation, fluid temperatures at the outlet of the modules are adjusted. This way, each module emulates every virtual component simulated by the software. Data exchanges are represented in Fig. 2.

\subsection{The SCSPT virtual environment and the weather test sequence generation}

The SCSPT has created a virtual environment to evaluate performance of combisystem with a 12 days test on the semi-virtual bench. The objective of the method is that the tested system use proportionately the same auxiliary energy during the test sequence ( $\left.Q_{12 \text { d,aux }}\right)$, as it would use during a complete year with the selected building and climate conditions $\left(Q_{\text {y,aux }}\right)$. So, the auxiliary energy annual consumption is evaluated by a simple extrapolation, as described by the following equation.
$Q_{\mathrm{y}, \text { aux }}=\frac{365}{12} \cdot Q_{12 \mathrm{~d} \text {,aux }}$

The virtual environment is made up of the building model defined in the IEA Solar Heating and Cooling programme Task 32 (Heimrath and Haller, 2007), a standard DHW draw offs profile and a specific 12 days weather data sequence selected from the annual weather data thanks to an optimisation algorithm.

The process for the selection of the weather data sequence is presented in (Albaric et al., 2008) and is the special feature of the SCSPT. It is based on TRNSYS simulations of the reference combisystem modelled within IEA-SHC Task 32 (Heimrath and Haller, 2007). The algorithm selects 12 days from the annual weather data file so that the two following criteria, internal storage energy and space heating demand, have the same evolution dayby-day during the test sequence as month-by-month during the annual sequence.

Once generated for a climate, the same weather data sequence is used to test any combisystem. The performance evaluation is available for the corresponding climate and the selected building model.

\subsection{Validation of the SCSPT}

The SCSPT approach has been tested within a French project and a European project Combisol (http:// www.combisol.eu) for various combisystems available on 
the market. The method has been especially studied in (Mette et al., 2010). To sum things up:

- Weather data selection relevancy has been validated through numerous TRNSYS simulations;

- Experimental results are close to CTSS results, when this one is adjusted, considering pipe heat losses and controller defaults;

- Performance evaluations for three tested combisystems are consistent with on-site monitoring results.

However, it seems impossible to characterise thermal performances of combisystems with the current SCSPT procedure. This paper proposes an extension of the SCSPT procedure to make it able to evaluate thermal performances of combisystems for other boundary conditions. The improvement relies on global model identification, analysing completely data recorded during the SCSPT test.

\section{Improvement of the procedure with global model identification}

The objective is to develop a procedure which is able to learn the behaviour of the tested combisystem from a 12 days test. Considering energy fluxes and temperatures as inputs and outputs of the system, a global model could be identified from an analysis of the test data. Such a model could be used to simulate the combisystem with various boundary conditions and then to evaluate its thermal performance whatever the conditions.

\subsection{The SCS global model}

The proposed model is represented in Fig. 3. It is mainly composed of one linear dynamic model with known equations ("White Box"), which estimates the states of the system for the next time step, and one non-linear static model to identify ("Black Box"), which represents the real specific behaviour of each system. More explanations are given below.

\subsubsection{Inputs and outputs of the global model}

The global model must evaluate the energy flows involved in a combisystem according to weather and load conditions. Therefore, inputs and outputs are defined as follows:

- Inputs are defined as external variables, i.e. all the variables that are not controlled by the system. Those are climate variables like ambient temperature and solar irradiations, and DHW loads data like cold-water temperature and DHW draw-offs.

- Outputs are defined as energy flows controlled by the system: on the one hand, heat supplied to space heating loop and DHW draw-offs; and on the other hand, energy supplied by the collector and the auxiliary energy. In this work, the auxiliary energy system is considered as part of the combisystem. Therefore, the energy used by auxiliary system is considered as an output of the model.

This set of variables is also chosen to represent combisystem behaviour as simply as possible, to help the model identification.

\subsubsection{Dynamical model representation}

One interesting representation of dynamical model in this case is the state space model. The general form of a state space model can be described by the following equation.

$\left\{\begin{array}{l}\dot{x}=g(x, u) \\ y=h(x, u)\end{array}\right.$

where y and $u$ are respectively outputs and inputs vectors of the model. $x$ is the state vector of the model. $g$ and $h$ are two functions, linear or not.

Analogy between this representation and the real functioning of solar combisystem has inspired the structure of

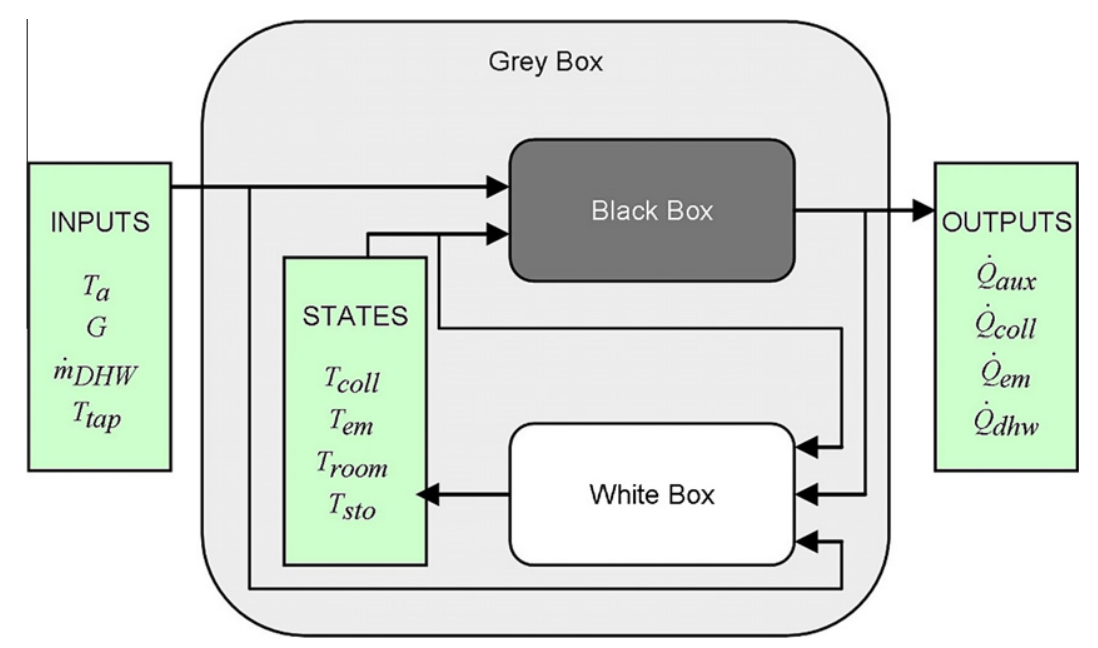

Fig. 3. The proposed global SCS model structure. 
the proposed model. Usually, heat flows are controlled depending on the temperature of various components part of the combisystem (collector, store, heat emitter, building rooms). They provide information about the energy needed, stored and available. Therefore, it seems relevant to consider those temperatures as the state of the system. It is even more interesting to use these temperatures as they can be estimated with well-known and simplified equations. The $\mathrm{g}$ function can so be expressed as a "White Box" model. The real special feature of each system to be tested by the SCSPT is how it manages energy according to external variables and its own states. The $\mathrm{h}$ function, identified from the test data analysis, is so a "Black Box" model. Observing most system controlling, it can be stated that the $\mathrm{h}$ function is non-linear. The whole model is a "Grey Box" model.

\subsubsection{The white box part}

The "White Box" part aims to evaluate mean temperature of the collector, the store, the heat emitter and the room of the building, from one time step to the next one. This must be done only with the set of variables presented in Section 3.1.1 and with standard parameters as far as possible.

The "White box" part presented below is the one currently used. Nevertheless, it is possible to envisage other models, as long as no other variable is required to provide evaluations of the temperatures needed.

For numerical computing, all equations described in Section 3.1.3.1 are calculated with an explicit discretization scheme and a 30 min time step.

3.1.3.1. Collector model. Eqs. (3) and (4) represent the model used to evaluate the mean temperature of the collector. It is described in Perers (1997). This model is based on the well-known "Hottel-Whillier-Bliss" equation for flat plate solar collectors that is adapted to characterise almost every kind of collectors, except ICS collectors. It has been widely used for simulation (Perers and Bales, 2002) and standards (EN 12975-2, 2006; ASHRAE 93-86, 1986).

$$
\begin{aligned}
c_{5} \frac{d T_{\text {coll }}}{d t}= & \dot{Q}_{\text {sol,net }}-\frac{\dot{Q}_{\text {coll }}}{A_{\text {coll }}} \\
\dot{Q}_{\text {sol,net }}= & F^{\prime}(\tau \alpha)_{\text {en }}\left(K_{\theta \mathrm{b}}(\theta) \cdot G_{\mathrm{b}}+K_{\theta \mathrm{d}} \cdot G_{\mathrm{d}}\right)-c_{6} v G \\
& -c_{1}\left(T_{\text {coll }}-T_{\mathrm{a}}\right)-c_{2}\left(T_{\text {coll }}-T_{\mathrm{a}}\right)^{2}-c_{3} v\left(T_{\text {coll }}\right. \\
& \left.-T_{\mathrm{a}}\right)+c_{4}\left(E_{\mathrm{L}}-\sigma T_{\mathrm{a}}^{4}\right)
\end{aligned}
$$

3.1.3.2. Heat emitter model. So far, tested combisystems have been designed to work with radiators. This part of the model must be adapted to be used with systems working with heating floor.

The radiator model used to evaluate the mean temperature of the heat emitter is based on standard parameters, calculated with (EN 442-2, 1996). A thermal capacitance has been added to take into account the dynamic behaviour:
$C_{\mathrm{em}} \frac{d T_{\mathrm{em}}}{d t}=-K\left(T_{\mathrm{em}}-T_{\text {room }}\right)^{n}+\dot{Q}_{\mathrm{em}}$

3.1.3.3. Building model. The building model used is the one defined in the international standard (ISO 13790:2008(E), 2008). Every heat transfer coefficients and the internal capacity can be calculated out of architectural and physical parameters of the building. The complete set of equation is not described in this paper but it can be found in the mentioned standard. Parameters of this model have been calculated and tuned in order to have similar results as the reference building described in IEA SHC Task32 (Heimrath and Haller, 2007): SFH30, SFH60 and SFH100 (i.e. single family house with space heating loads respectively of $30 \mathrm{~kW} \mathrm{~h} \mathrm{~m}^{-2}, 60 \mathrm{~kW} \mathrm{~h} \mathrm{~m}^{-2}$ and $100 \mathrm{~kW} \mathrm{~h} \mathrm{~m}^{-2}$ over a year for the Zurich climate).

3.1.3.4. Store model. As the store is one of the central components of a combisystem, this part is not modelled during the SCSPT, unlike the other components presented in the above sections.

The goal of this model is to provide information about the energy stored in the tank. Given that only few variables and parameters are available, equations come down to a simple energy balance, completed by a heat capacitance and heat loss parameters:

$$
\begin{aligned}
C_{\text {sto }} \frac{d T_{\text {sto }}}{d t}= & \dot{Q}_{\text {aux }, \text { sto }}+\dot{Q}_{\text {coll, sto }}-\dot{Q}_{\text {em }, \text { sto }}-\dot{Q}_{\text {dhw }, \text { sto }} \\
& -(\mathrm{UA})_{\text {sto }}\left(T_{\text {sto }}-T_{\text {amb,sto }}\right)
\end{aligned}
$$

In this equation, heat flows take into account heat losses of pipes. Only gross estimations of the heat losses can be done for each loop with the variables available. They consider both hot and cold side of each loop, giving them a heat loss coefficient and a representative temperature. Losses are cancelled when no heat is delivered through pipes.

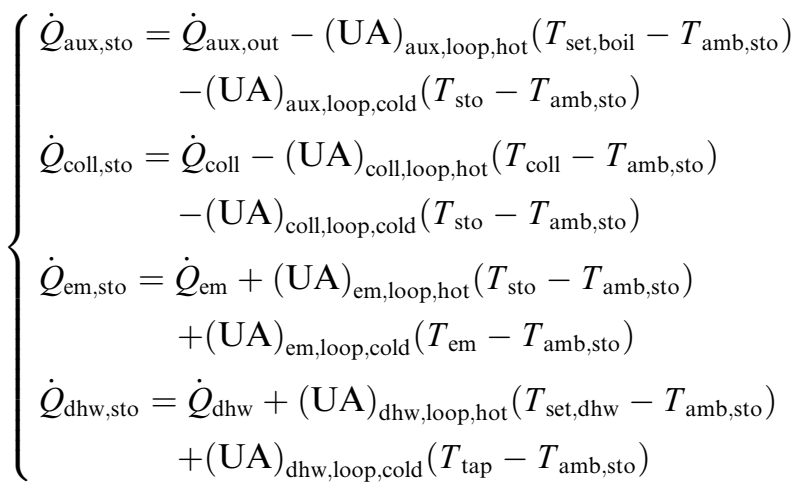

3.1.3.5. Auxiliary energy model. The "White Box" model takes $Q_{\text {aux }}$, the auxiliary energy used by the SCS, as input. Yet, the store model needs $Q_{\text {aux,out }}$, the heat supplied by the auxiliary part. Thus, a simplified model describing the auxiliary system is required to evaluate its efficiency. 
So far, tested combisystems have been combined with auxiliary gas boilers. This part of the model must be adapted to be used with other kind of auxiliary energy.

The gas boiler model used in the "White Box" part is derived from the model used in the French thermal regulation for building (RT2005, 2005). This model evaluates the energy losses of the boiler according to the heat demanded with a simple second-order polynomial. The relationship between the energy input and output of the boiler can be expressed as follows:

$\dot{Q}_{\text {aux }}=a_{\text {aux }} \dot{Q}_{\text {aux }, \text { out }}^{2}+\left(1+b_{\text {aux }}\right) \dot{Q}_{\text {aux }, \text { out }}+c_{\text {aux }}$

Parameters $a_{\text {aux }}, b_{\text {aux }}$ and $c_{\text {aux }}$ are calculated with characteristic powers and losses of the boiler. Calculations are available in the French regulation. $Q_{\text {aux,out }}$ is determined by solving simply the quadratic equation. The nearest root to $Q_{\text {aux }}$ is taken as the solution.

\subsubsection{The black box part}

The "Black Box" part aims to model the tested combisystem behaviour, i.e. how it manages energy according to external variables and its own states (temperatures described in Section 3.1.3 above).

Since combisystem behaviours are complex and non-linear, it seems appropriate to include in this "Black Box" part, a powerful mathematical model such as an Artificial Neural Network (ANN). ANNs are widely used nowadays because, as (Kalogirou, 2001) highlights, they can learn from examples, are fault tolerant and are able to deal with non-linear problems. They are even widely used in solar energy fields for predicting complex phenomenon and modelling solar components as well as complete solar system.

Mellit and Massi Pavan (2010) and Paoli et al. (2010) have used ANNs to forecast daily solar radiation, both to predict performance of grid connected PV plant (at Trieste for the former, Ajaccio for the latter). They have built different neural network architectures but results are relevant for both authors. Paoli has even found that ANNs are more precise compared to conventional prediction methods.

Baccoli et al. (2010) has inferred the steady state performances of a thermal solar collector with evacuated pipes, only from a 4 days experimental data set of the collector in transient regime. He has tried two kind of model: a grey box model (based on known physical model and parameters identification) and a Dynamic Adaptative Neural Network. Both models have shown good results compared to the official EN 12975 efficiency curve.

Medinelli Sanino and Rojas Reischel (2007) has modelled a solar domestic water heating system located near Viña del Mar, Chile. After testing different model structures, the author turns to semi-physical modelling combined with ANN: available system knowledge helps to organise the conceptual form and ANN adjusts that knowledge into a particular non-linear model structure. According to the authors, this incorporation of physical knowledge is advantageous because it shares advantages of each one of the structures, providing a model at the same time parsimonious and flexible. The so trained model predicts with good accuracy the mean water temperature of the storage tank.

Many other examples are reviewed in (Kalogirou, 2001) but those presented above emphasise some interesting points:

- Complex phenomenon, like solar radiation, can be modelled by ANN and can even be more precise than usual prediction method.

- Modelling and predicting global system performances seem possible. It has been done for different kind of solar domestic water heating systems.

- Integrating knowledge of the system as far as possible is advantageous when modelling systems.

So far, nothing has been done to link ANN modelling with SCS. These points encourage to consider the global model structure presented in this paper and especially to integrate ANN in the "Black Box" part of the model.

ANNs are numerical model inspired by biological neural networks. They build their knowledge through a learning process that strengthens connections between neurones, like a brain.

The structure of a mathematical neurone is represented in Fig. 4 and is described in Dreyfus et al. (2002). Neurone inputs $x_{\mathrm{i}}$ came from other neurones outputs or model inputs. Those signals are transmitted to the neurone through connections called "synapses". Synaptic weights $w_{\mathrm{i}}$ are linked to each connection. There are several ways to combine inputs with their corresponding synaptic weights. In this model, a simple linear combination as described in Eq. (9) is used. The result of this combination $v$ is the argument of a transfer function $f$. The outcome $y$ is the activation of the neurone.

$$
\begin{aligned}
& v=w_{0}+\sum_{i=1}^{n-1} w_{i} x_{i} \\
& y=f(v)
\end{aligned}
$$

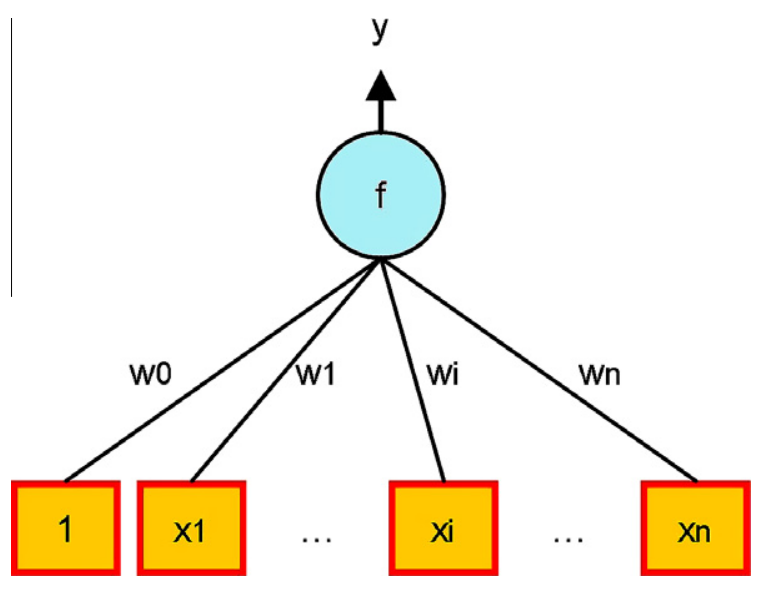

Fig. 4. Scheme of a mathematical neurone. 


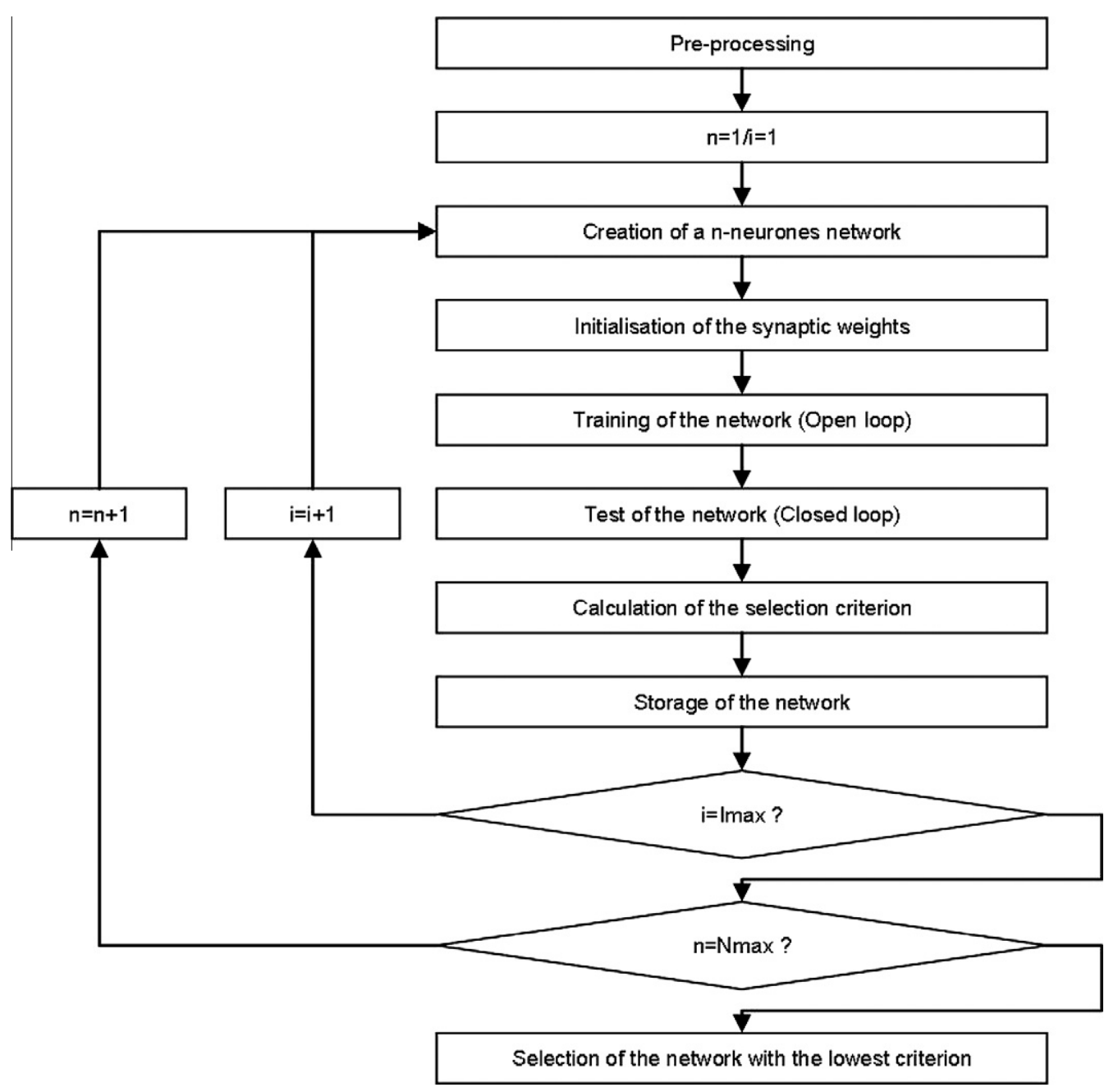

Fig. 5. Scheme of the process for training and selection of a SCS global model.

ANNs are built linking neurones together and with the model inputs and outputs. When presenting a training data set, an optimisation algorithm searches the best synaptic weights set to minimise a cost function. All functions and parameters selected for the neural network training of this model are presented in Section 3.2.

\subsection{Identification of the model}

Once the training data set is obtained from the lab test, it is used to train several neural networks. Then, the same training set helps finding the best ANN to make the complete SCS model reproduce the system behaviour as faithfully as possible. The complete process of training and selection is represented in Fig. 5 and described below.

\subsubsection{Pre-processing of inputs and outputs}

The training set is processed to have data with a $30 \mathrm{~min}$ time step. The "White Box" model is applied to the complete data set to have estimations of the system's states during the lab test. This includes "White Box" part errors as input of the neural network so that it learns to manage them.
Dreyfus et al. (2002) suggest normalising inputs and outputs. Ideally, variables should be centred and reduced. Another way proposed here to come close to this data reduction is to combine variables and parameters of the system and its environment. This way, inputs and outputs of the ANN are not raw temperatures and heat flows but reduced criterions of the interaction between the system, the building and the climate. The current proposed inputs and outputs reduction is described in the following equation.

$$
\begin{gathered}
u=\left[\begin{array}{c}
\dot{Q}_{\text {sol,net }} / \dot{Q}_{\text {sol,ref }} \\
K\left(T_{\text {em }}-T_{\text {room }}\right)^{n} / \dot{Q}_{\mathrm{d}} \\
\left(T_{\text {room }}-T_{\text {set,room }}\right) /\left(T_{\text {set,room }}-T_{\mathrm{a}, \mathrm{d}}\right) \\
\left(T_{\text {room }}-T_{\mathrm{a}}\right) /\left(T_{\text {set, }, \text { room }}-T_{\mathrm{a}, \mathrm{d}}\right) \\
\left(T_{\text {sto }}-T_{\text {set,dhw }}\right) / 100
\end{array}\right] \\
y=\left[\begin{array}{c}
\dot{Q}_{\text {aux }} / \dot{Q}_{\text {aux }, \text { nom }} \\
\dot{Q}_{\text {coll }} /\left(A_{\text {coll }} \dot{Q}_{\text {sol,ref }}\right) \\
\dot{Q}_{\text {em }} / \dot{Q}_{\mathrm{d}}
\end{array}\right]
\end{gathered}
$$

$Q_{\text {sol,net }}$, the net solar irradiance on the collector defined in Eq. (4) and $Q_{\text {coll }}$, the heat supplied by the collector are both divided by a reference solar irradiance taken at 
$1000 \mathrm{~W} / \mathrm{m}^{2} . Q_{\mathrm{em}}$ the heat received by the radiator and $K\left(T_{\mathrm{em}}-T_{\text {room }}\right)^{n}$, the heat transferred from the radiator to the room are divided by $Q_{\mathrm{d}}$, the standard heat load of the building, which depends also on the climate. $T_{\text {room }}$ is compared with the set room temperature and the ambient temperature. Both comparisons are divided by a reference temperature difference that takes into account the set room temperature and the design ambient temperature of the building heating system. $Q_{\text {aux }}$ is simply divided by the nominal power of the auxiliary energy system. Since there is no obvious reference temperature in relationship with the mean store temperature, $T_{\text {sto }}$ is compare with the DHW set point temperature and divided by 100 , which is the difference between the boiling and the melting point of water at standard pressure.

The DHW demand is not taken into account at the bounds of the neural network. So far, none of the tested or simulated SCS has shown difficulties to meet the demand. In order to have an ANN as simple as possible and to have a first validation of this approach, the current hypothesis is that the system is able to supply DHW at the desired temperature $T_{\text {set,dhw }}$. So the output $Q_{\mathrm{dhw}}$ is simply calculated and only affects the store model in the "White Box" part. In the next steps of the project, this aspect must be taken into account.

\subsubsection{Construction of the ANN structure}

The ANNs tested for the "Black Box" part of the model are simple static Multi Layer Perceptrons (MLPs). By means of trial and errors, a more precise structure is set to limit the number of ANNs to test. The activation function for every neurone is a hyperbolic tangent. Only one layer of hidden neurone is considered. The structure of tested ANNs is represented in Fig. 6. Finally, tested ANNs differ in the number of neurones in the hidden layer.

\subsubsection{Determination of the maximum number of neurones}

The main issue of ANN modelling is to find the correct number of neurones. With too few neurones, the ANN will not be able to learn enough the process. However, with too many neurones, the ANN will learn well the training data set but will not be able to generalise for other simulations.

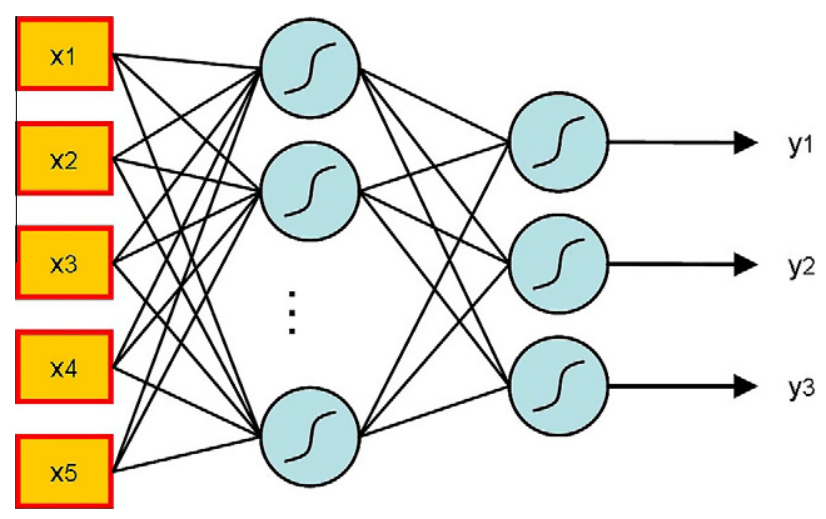

Fig. 6. Structure of the trained ANNs.
This number is strongly dependent on the process to model.

So far, there is no rule to find the right number of neurones. It is a matter of trial and error. Nevertheless, to develop an automatic way to find the best ANN for the tested SCS, it is possible to refer to the Widrow rule of thumb described in Widrow and Stearns (1985): the number of training patterns $N_{\text {tp }}$ must be larger than $N_{\text {sw }}$, the number of synaptic weights to be identified, divided by the error tolerance $\varepsilon_{\text {tol }}$.

$N_{\text {tp }} \geqslant \frac{N_{\text {sw }}}{\varepsilon_{\text {tol }}}$

From this rule, a maximum number of hidden neurones can be calculated. Since only one hidden layer is considered in this ANN (see Section 3.2.2) and that a bias is added to each neurone (including output neurones), $N_{\mathrm{sw}}$ can be expressed with $N_{\mathrm{i}}$, the number of inputs, $N_{\mathrm{o}}$, the number of outputs and $N_{\mathrm{n}}$, the number of neurones.

$$
\begin{aligned}
N_{\mathrm{sw}} & =\left(N_{\mathrm{i}}+1\right) \cdot N_{\mathrm{n}}+\left(N_{\mathrm{n}}+1\right) \cdot N_{\mathrm{o}} \\
& =N_{\mathrm{n}} \cdot\left(N_{\mathrm{i}}+N_{\mathrm{o}}+1\right)+N_{\mathrm{o}}
\end{aligned}
$$

Therefore, the maximum number of hidden neurones is expressed as follows:

$N_{\mathrm{n}, \max }=\frac{\varepsilon_{\mathrm{tol}} \cdot N_{\mathrm{tp}}-N_{\mathrm{o}}}{N_{\mathrm{i}}+N_{\mathrm{o}}+1}$

During the selection process, networks with complexities going from 1 to $N_{\mathrm{n}, \max }$ neurones will be trained.

\subsubsection{Initialisation of the synaptic weights}

Initial synaptic weights of the ANN are determinant for the optimisation algorithm convergence and the solution found. Several initialisations of ANNs are tested in this process $\left(I_{\max }\right)$.

Some weights initialisation methods enhance ANN training. The one used in this process is the Nguyen-Widrow method (Nguyen and Widrow, 1990).

\subsubsection{Training algorithm (open loop)}

Optimisation algorithms search for the best synaptic weights set to minimise a cost function. The cost function $J$ chosen here is the sum of squared errors over the training data set.

$J=\sum_{i=1}^{N_{\mathrm{tp}}}\left(y_{i}-\tilde{y}_{i}\right)^{2}$

Most training algorithms are based on the calculation of the gradient of the cost function. In the case of feedforward network with differentiable activation function for every neurone (like the MLP considered here), this gradient can be smartly calculated with the backpropagation technique (Rumelhart et al., 1986). To improve algorithm speed compared to a simple steepest descent method, the LevenbergMarquardt algorithm (Marquardt, 1963) is chosen. It calculates an estimation of the inverse of the Hessian matrix 
$H$ of the cost function and changes the step $\lambda$ at each iteration. The recurrence relation is described by the following equation.

$w_{j+1}=w_{j}-\left(\tilde{H}\left(w_{j}\right)+\lambda_{i} I\right)^{-1} \cdot \nabla J\left(w_{j}\right)$

To avoid an overtraining phenomenon, a "regularization" strategy has been chosen in the training process using Bayesian regularization in complement of the LevenbergMarquardt algorithm (Mackay, 1992).

\subsubsection{Test of the neural network (closed loop)}

It is possible to test the trained network generalisation to a certain extent with the same training data set. The ANN has learnt the SCS behaviour in an "Open loop" way, i.e. with fixed ideal states calculated in the pre-processing step (see Section 3.2.1). It is interesting to check whether the global model is stable and precise in a "Closed loop" simulation of the training data set. In this case, ANN errors affect the state estimation of the "White Box" part of the global model. This way, the network shows if it can handle its own errors. A still overtrained network will be excluded in this step.

\subsubsection{Selection criterion}

ANNs with different complexities and different initialisations are trained in this process. To select the best one, they are compared according to two criterions.

The Root Mean Square Error (RMSE) assesses the estimation quality of the model at each time step. This is the criterion commonly used to evaluate an estimator in statistics.

$\mathrm{RMSE}=\frac{1}{N_{\mathrm{tp}}} \sum_{i=1}^{N_{t p}}\left(y_{i}-\tilde{y}_{i}\right)^{2}$

The quality expected for this kind of model is above all to estimate precisely the global energy involved by the SCS during any simulation. Even if occasional large errors happen, the model could be able to evaluate with a good accuracy the auxiliary energy used for a complete year. Therefore, it is interesting to check the global estimation error.

$\operatorname{Err}=1-\frac{\sum_{i=1}^{N_{\mathrm{tp}}} \tilde{y}_{i}}{\sum_{i=1}^{N_{\mathrm{tp}}} y_{i}}$

To observe both expected model quality as only one criterion, a coefficient $d$ is introduced: it combines RMSE and Err as follows

$d=\sqrt{\left(\frac{\mathrm{RMSE}}{\alpha_{\mathrm{RMSE}}}\right)^{2}+\left(\frac{\mathrm{Err}}{\alpha_{\mathrm{Err}}}\right)^{2}}$

where $\alpha_{\text {RMSE }}$ and $\alpha_{\text {Err }}$ are fixed coefficients which assigned a different weight for RMSE and Err. So far, they were arbitrarily set respectively to 5 and 0.9 .

Among all networks trained (see Sections 3.2.3 and 3.2.4), the one that gives the lowest $d$ coefficient when simulating the training sequence is selected to be part of the final "Grey Box" model of the tested combisystem.

\subsection{Final procedure}

Considering the modelling aspect proposed in this paper to improve the SCSPT, the procedure to evaluate SCS performances can be summed up as follows:

- Install the SCS on the semi-virtual test bench as it is installed in a real building.

- Collect parameters needed for the "White Box" (especially storage and auxiliary energy parameters).

- Carry out the test with the virtual environment corresponding to the 12 days Zurich climate sequence, the SFH60 radiator and building parameters and with the collector parameters suggested by the manufacturer. Models are all defined in Section 3.1.3.

- Collect data needed for the model training during the test sequence.

- Apply the process defined in Section 3.2 to get a global model of the tested SCS.

- Simulate the SCS behaviour over a year with different buildings, climates and collector areas.

- Characterise the SCS with the FSC method (Letz et al., 2009).

The FSC method considers that fractional energy savings $f_{\text {sav }}$ of a SCS can be expressed as a quadratic function of the fractional solar consumption FSC, a dimensionless quantity which only depends on the environment of the SCS. Thus, the performances of the tested SCS are characterised by a simple parabola.

\section{Results and discussion}

\subsection{Numerical results}

First, to validate this new approach, data from simulations of three different SCS model were used to train global models as described in Section 3.2. Simulations were done with TRNSYS (Klein et al., 1994).

\subsubsection{SCS TRNSYS models}

The three detailed models used for this numerical evaluation can be briefly described as follows.

- SCS1 is the reference system modelled during the IEA SHC Task 32 (Heimrath and Haller, 2007). It is represented in Fig. 7. The model does not consider DHW loop and space heating loop losses.

- SCS2 and SCS3 are commercial systems models used during the Combisol project (Mette et al., 2010). They can be represented by the generic SCS scheme B1 (Fig. 8) according to (Thür et al., 2010). Both systems differ in their controls and their heat store charging strategies (SCS3 use a special stratification device). No losses are considered in the loops. 


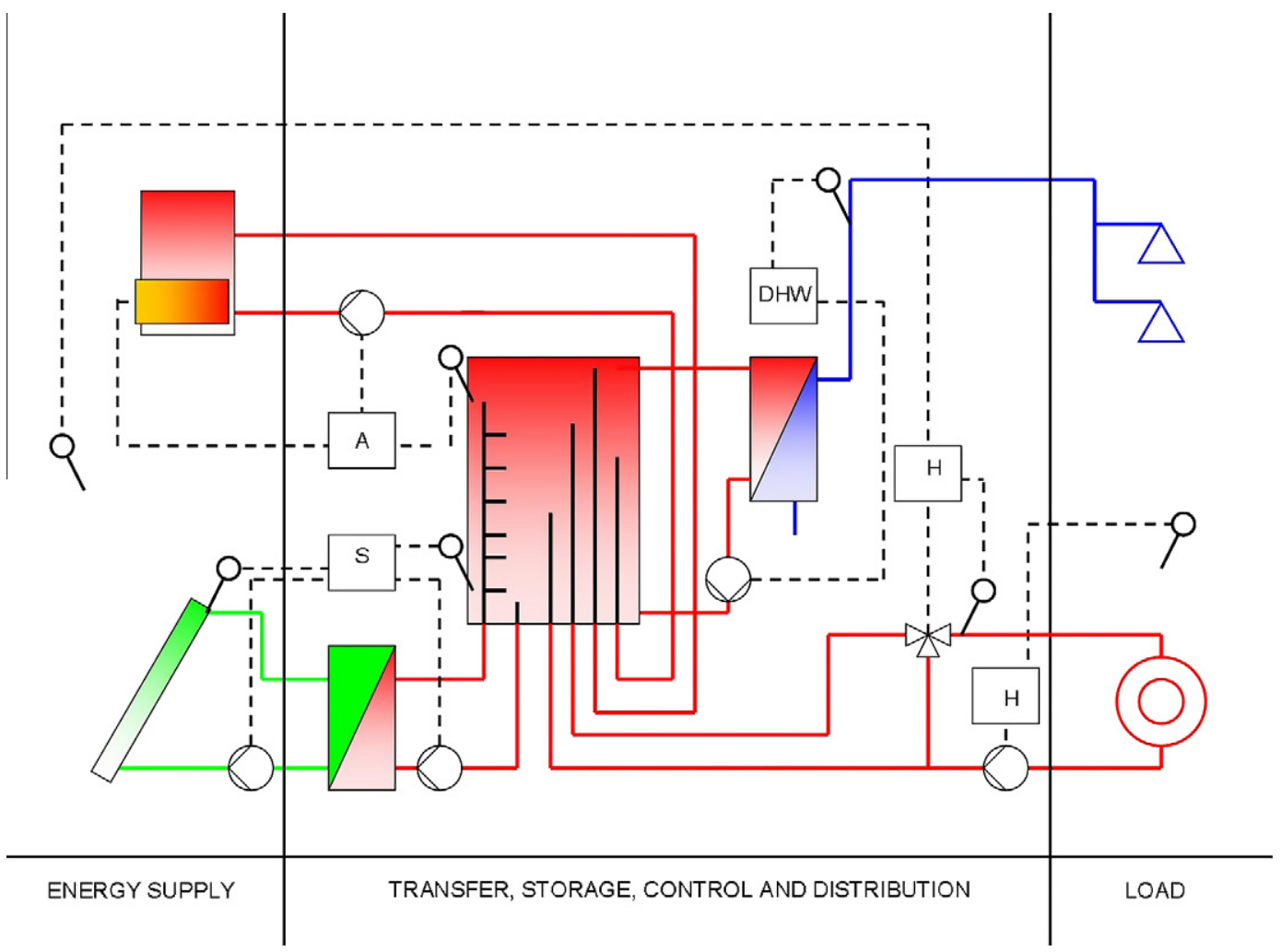

Fig. 7. Generic scheme of the reference combisystem model.

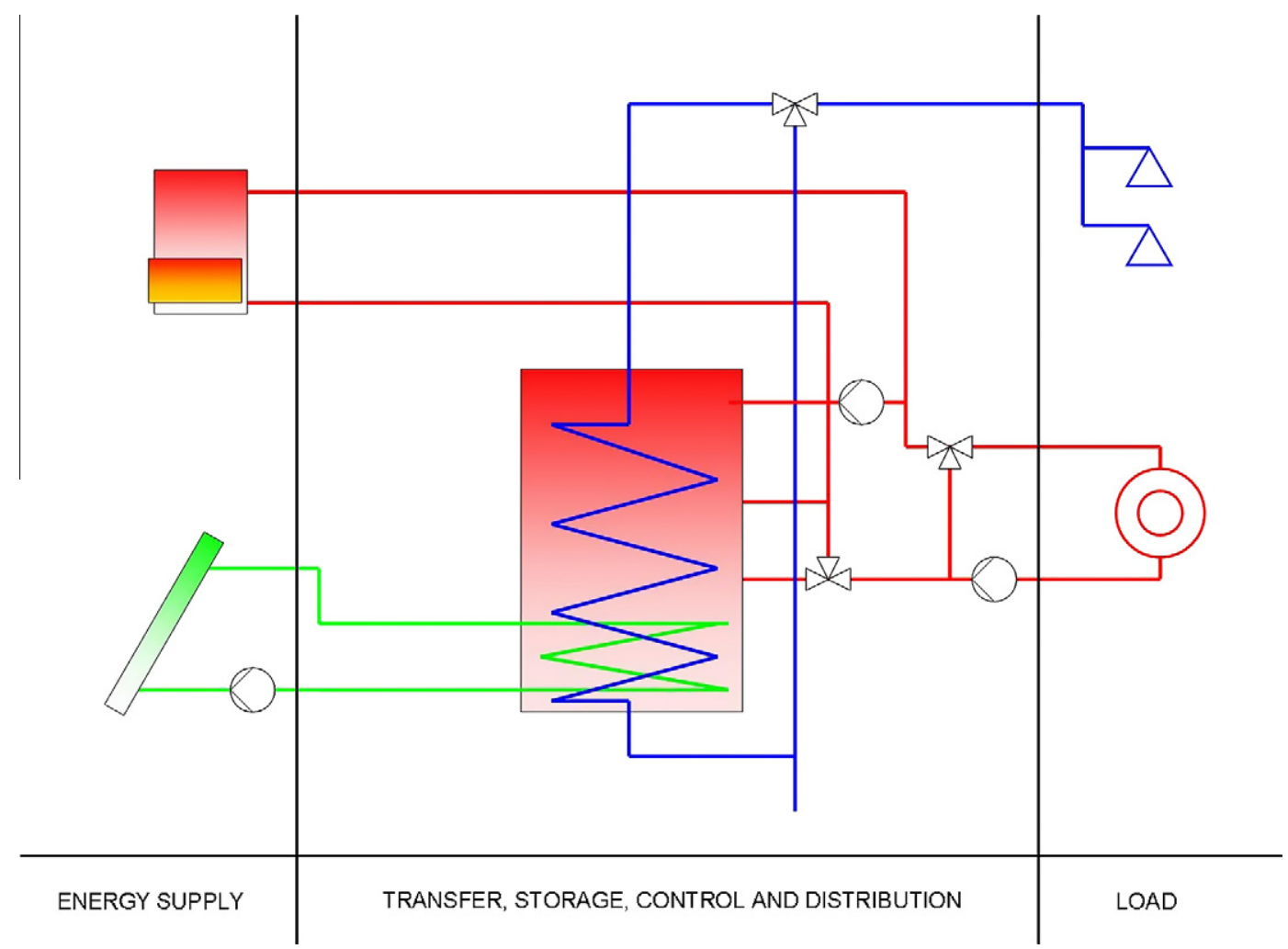

Fig. 8. Combisol generic scheme B1: immersed DHW Heat exchanger - auxiliary as return flow increase. 
Table 1

Climates, buildings and collector areas used for the 27 simulations of SCS characterisation.

\begin{tabular}{lll}
\hline Climate & Building & ${\text { Collector } \text { area }^{\mathrm{a}}\left(\mathrm{m}^{2}\right)}$ \\
\hline Barcelona & SFH30 & 10 \\
Zurich & SFH60 & 15 \\
Stockholm & SFH100 & 20 \\
\hline
\end{tabular}

${ }^{a}$ When changing the collector area, the design mass flow-rate in the collector loop and the store volume also change according to fixed ratios specified by the manufacturer (respectively $15 \mathrm{~kg} \mathrm{~h}^{-1} \mathrm{~m}^{-2}$ and $50 \mathrm{~L} \mathrm{~m}^{-2}$ for the reference SCS for example).

\subsubsection{Comparison with TRNSYS calculations}

For each SCS model, the SCSPT test (corresponding to the Zurich climate and the SFH60 building) has been simulated within TRNSYS. Then, data from this simulation have been used to train and select one global "Grey Box" model, according to the procedure describe in Section 3.2.

Global models have then been used to do the 27 annual simulations as described in Table 1. In Figs. 9-11, results are compared to the corresponding detailed models simulations within TRNSYS. Each simulation is represented by three points: $Q_{\text {aux }}$ (circles), $Q_{\text {coll }}$ (dots) and $Q_{\text {em }}$ (stars). On the whole, identified models and TRNSYS simulations are very close. Differences between both methods to estimate characteristic heats and energy are almost within the $\pm 10 \%$ range for all simulations. For low heat demand simulations, absolute differences are not excessive but the low energy level makes those differences proportionally higher.

Correlations coefficients $(R 2)$ are close to 1 except for $Q_{\text {coll }}$. This output seems harder to evaluate precisely. In SCS working, the annual energy coming from the collector depends not only on the quantity of heat stored in the tank (measured by $T_{\text {store }}$ ) but also on the quality of the heat stored (linked to the good stratification in the tank). The store model used in the "White Box" part does not take this aspect into account. Another more detailed store model may enhance $Q_{\text {coll }}$ evaluation accuracy. Moreover,

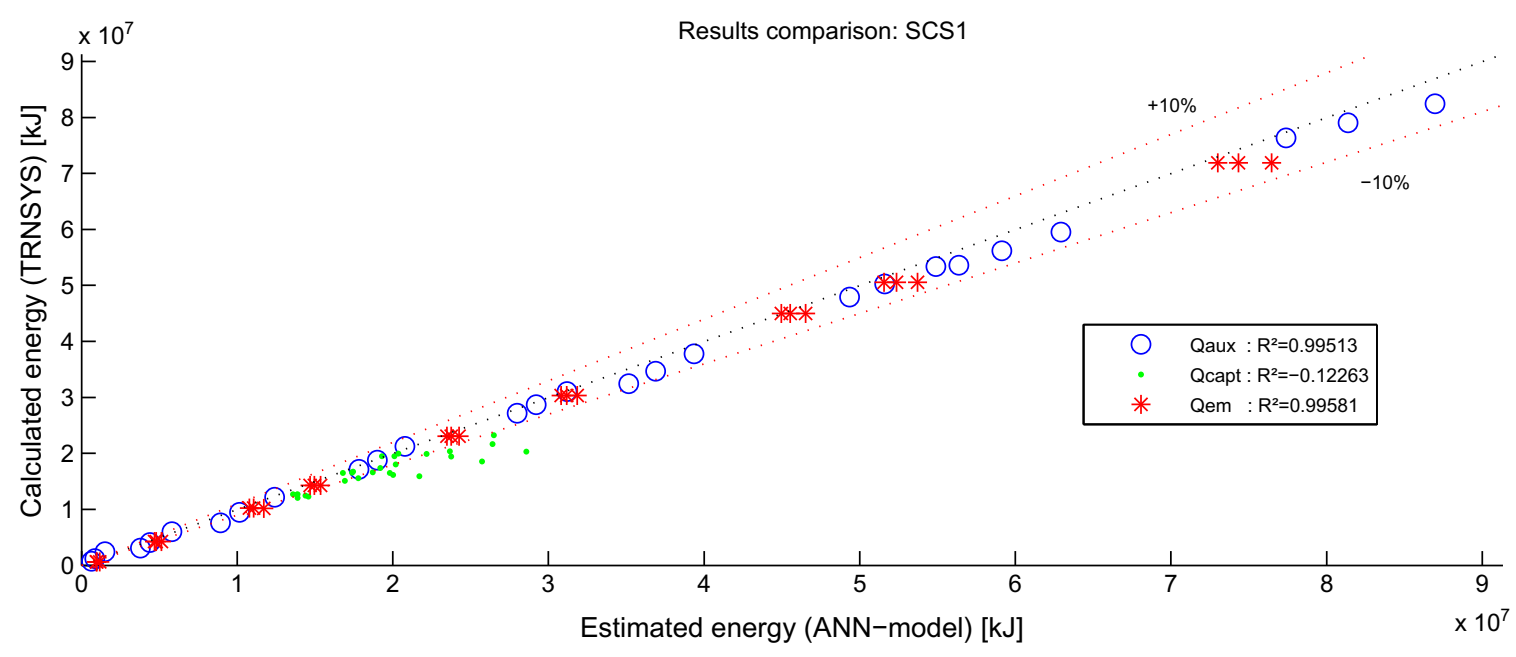

Fig. 9. Results of SCS1 energy estimations.

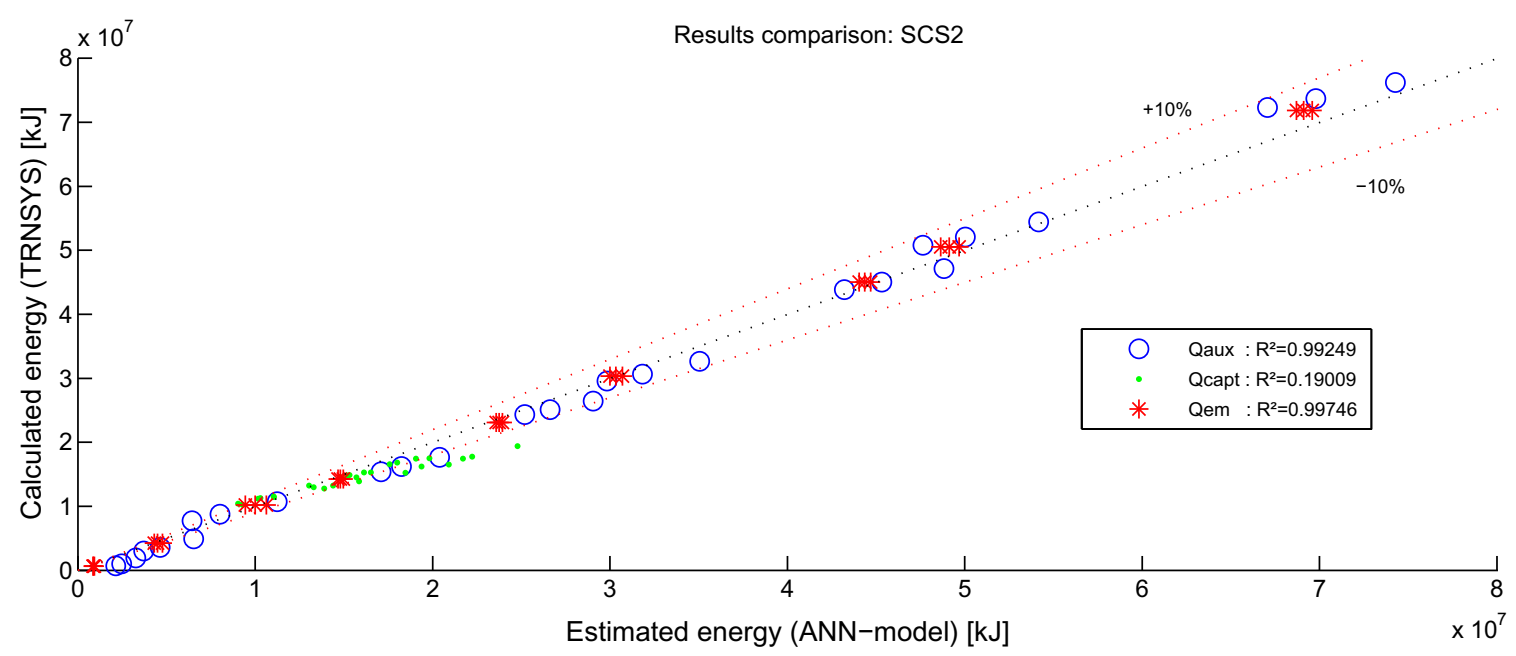

Fig. 10. Results of SCS2 energy estimations. 


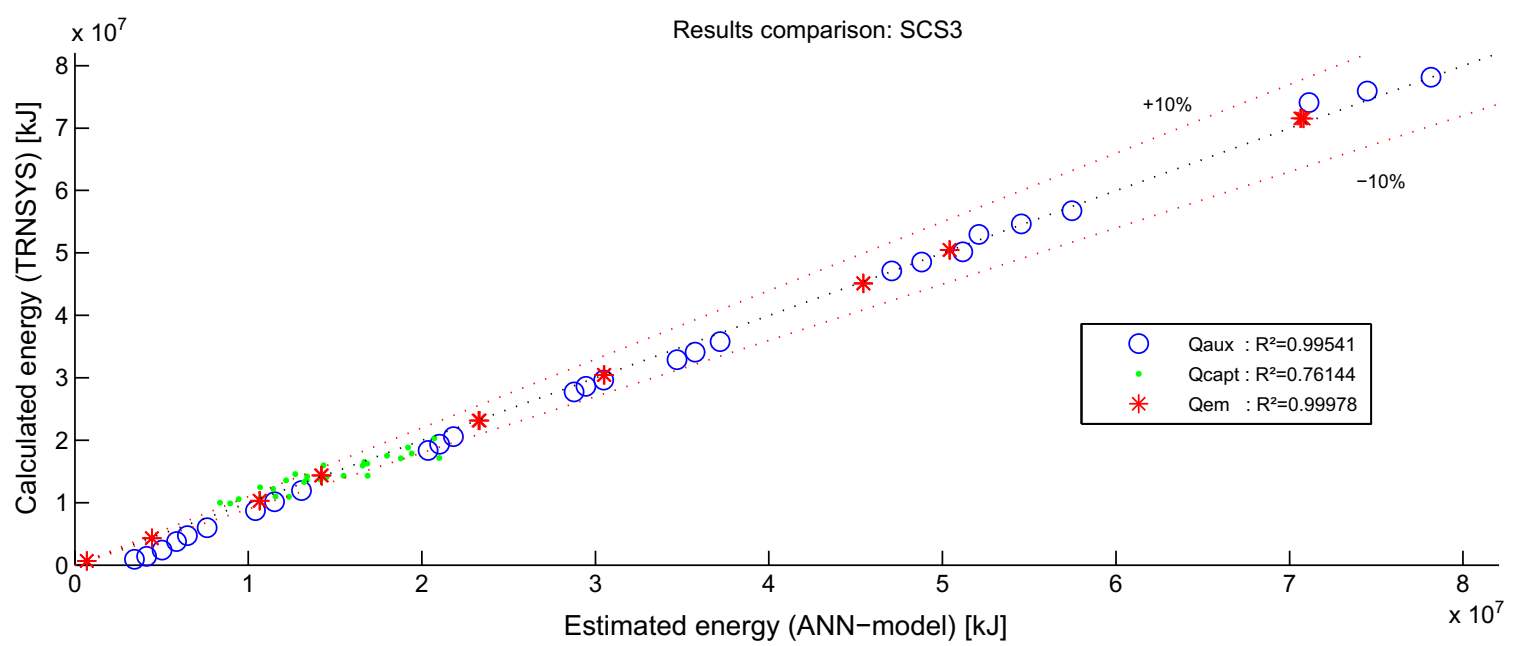

Fig. 11. Results of SCS3 energy estimations.

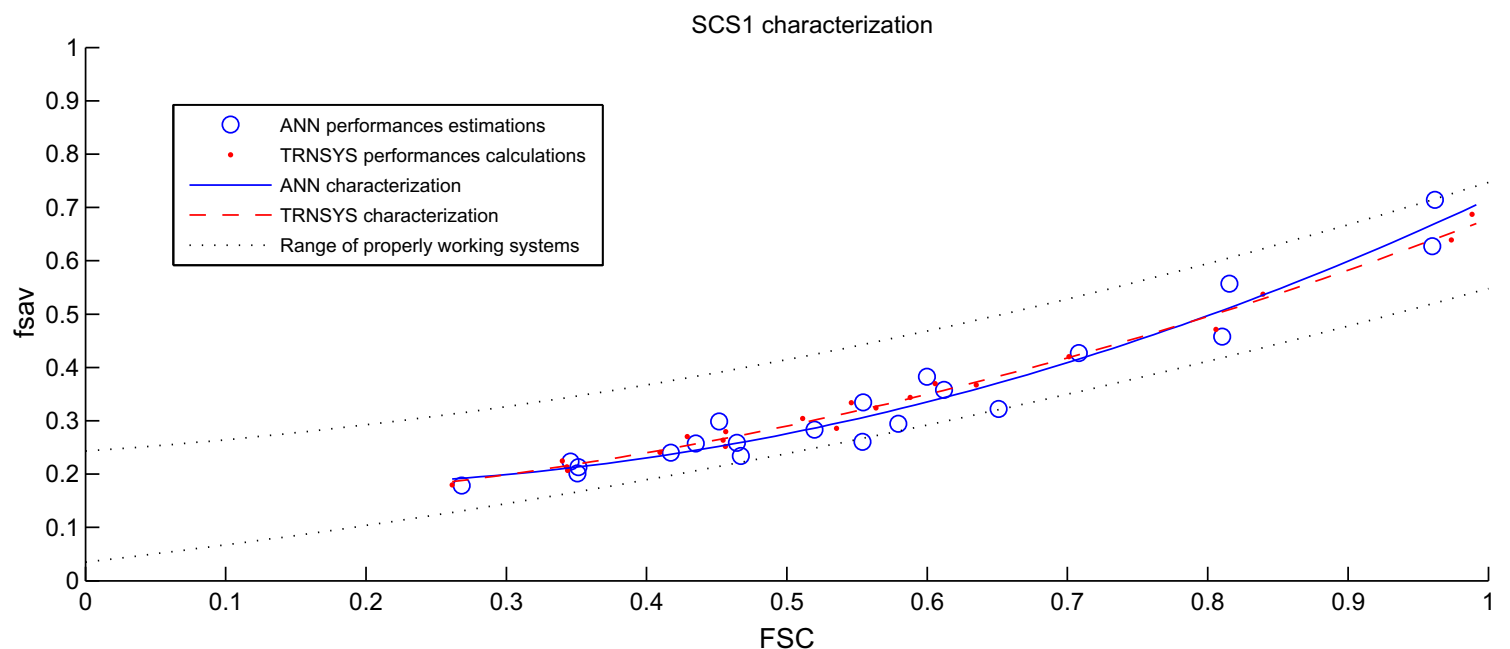

Fig. 12. Results of SCS1 characterisation.

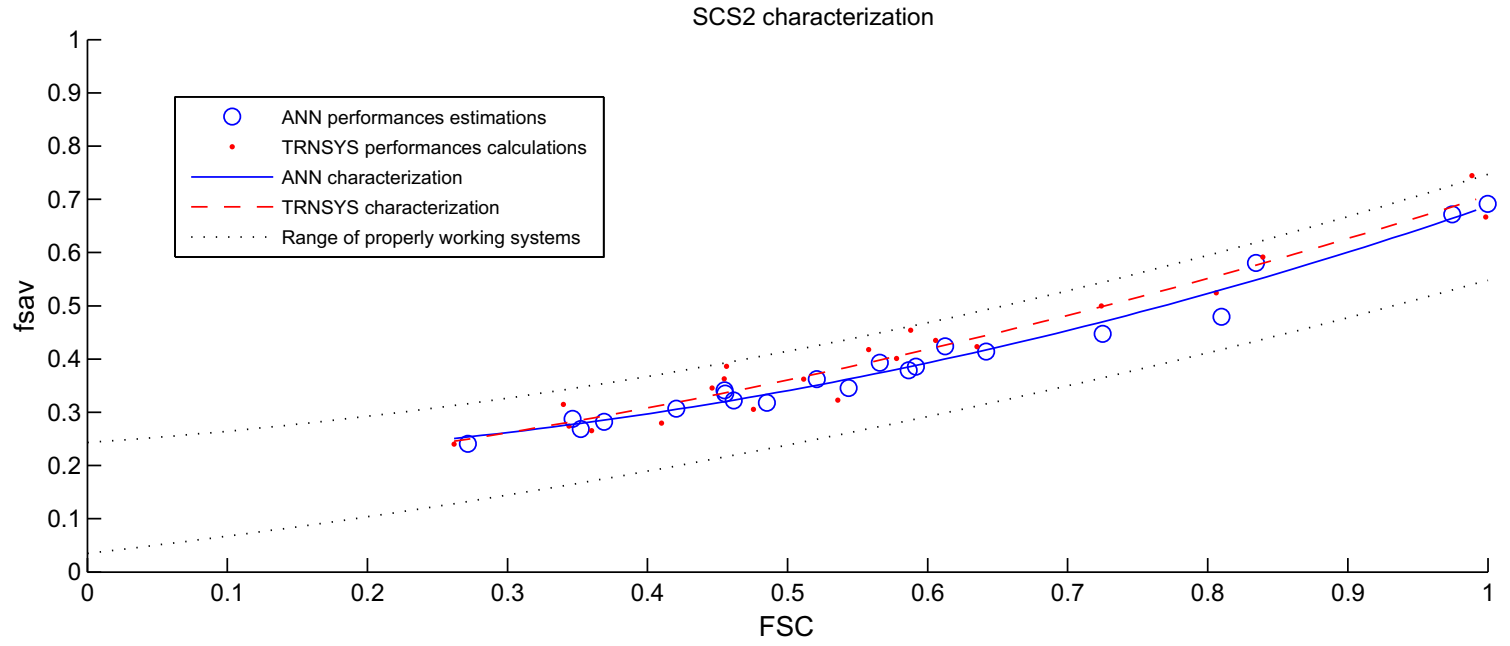

Fig. 13. Results of SCS2 characterisation. 


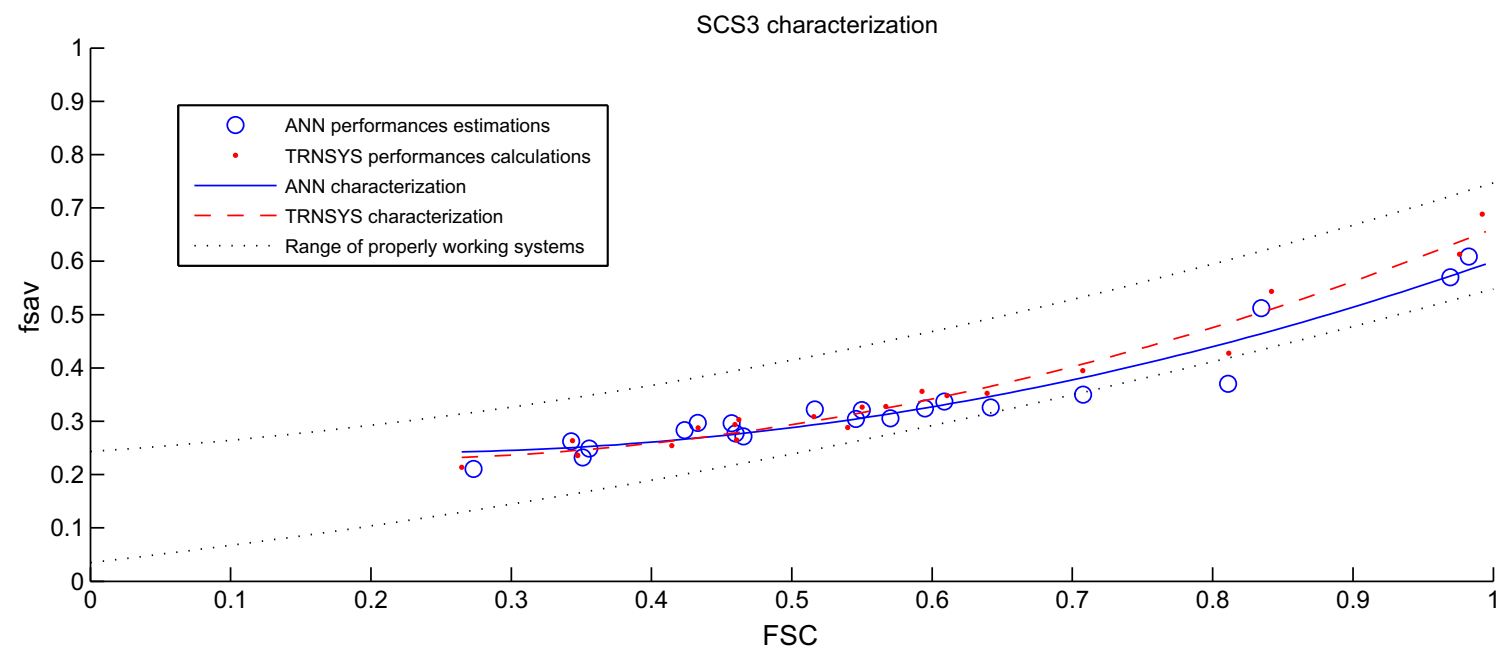

Fig. 14. Results of SCS3 characterisation.

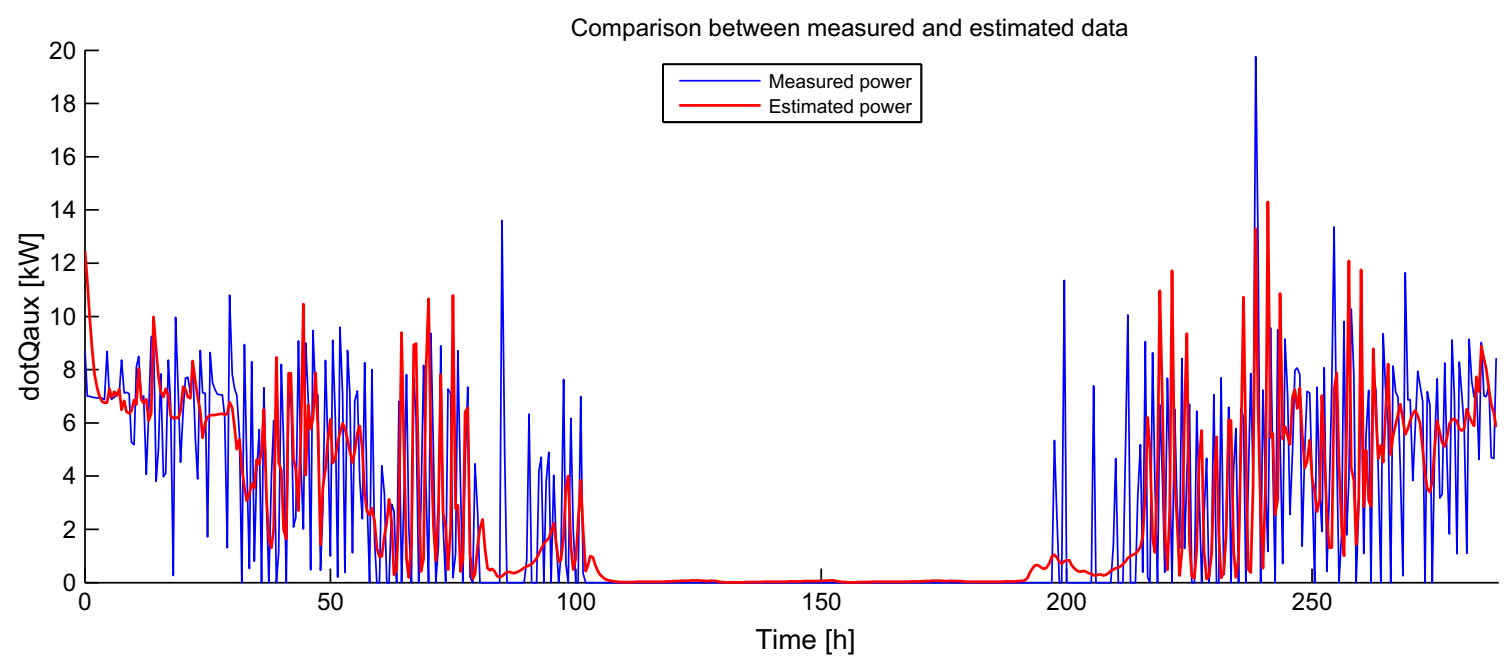

Fig. 15. Comparison between the experimental validation sequence of the real tested SCS and its grey box model.

estimations are less accurate for extreme conditions, i.e. for simulations combining Barcelona climate and a large collector area. In these cases, SCS, facing very low heat load, high solar gains and a storage almost full all year long, can behave very differently compared to their behaviours observed during the training sequence. That is most probably why the global grey box model overestimates $Q_{\text {coll }}$ for those simulations, resulting in a bad correlation coefficient.

In Figs. 12-14, each combisystem is characterised from TRNSYS results and global model results, according to the FSC method (Letz et al., 2009). Characteristic curves are close for the three combisystems models. Observation made above for energy estimations impacts on the characterisation. Curves are closer when FSC is below 0.6. For simulations with higher FSC, the SCS behaviour start to be different compared to the training set. Low power consumptions enlarge proportional errors. Nevertheless, estimated results are acceptable.

\subsection{Experimental results}

\subsubsection{The tested SCS}

A real combisystem has been tested according to this procedure on the INES test bench. As SSC2 and SSC3 numerical models, this system can be represented by the generic scheme B1 (Fig. 8). The store volume is larger (1000 L).

Two tests have been done for this combisystem, with different virtual environments:

(1) The standard 12 days test with the Zurich climate, the SFH60 building and $16 \mathrm{~m}^{2}$ of collector area. 
Table 2

Energy outputs comparison between measured data of test no. 2 and its model evaluation.

\begin{tabular}{llll}
\hline & $Q_{\text {aux }}$ & $Q_{\text {capt }}$ & $Q_{\text {em }}$ \\
\hline Measured (kJ) & $2.98 \times 10^{6}$ & $3.35 \times 10^{5}$ & $2.68 \times 10^{6}$ \\
Evaluated (ANN model) (kJ) & $2.94 \times 10^{6}$ & $5.35 \times 10^{5}$ & $2.73 \times 10^{6}$ \\
Difference (kJ) & $4.35 \times 10^{4}$ & $-1.99 \times 10^{5}$ & $-4.97 \times 10^{4}$ \\
Error (\%) & $1.46 \%$ & $-59.72 \%$ & $-1.85 \%$ \\
\hline
\end{tabular}

(2) The 12 days test corresponding to the Stockholm climate, the SFH100 building and $10 \mathrm{~m}^{2}$ of collector area.

\subsubsection{Comparison between the two tests sequence}

The former standard test data have been used to train and select a global model of the tested combisystem. The resulting model has been used to simulate the 2 nd test sequence.

Comparison between the global model simulation and the real recorded power consumption are presented in Fig. 15. It shows that the dynamic behaviour of the global model is in the whole quite corresponding to the real system. Even though model estimation does not fluctuate exactly in the same way as the real system did during the test, power variations are corresponding in average.

Table 2 shows that energy estimations are accurate for $Q_{\text {aux }}$ and $Q_{\text {em }}$. The error with $Q_{\text {coll }}$ is higher. The "Grey Box" model seems to overestimate the solar gains and compensate this overestimation through the two other energies. The difference is acceptable because the level of this output is low compared to the others. Observations made about $Q_{\text {coll }}$ estimations in Section 4.1.2 are still valid in this case. Nevertheless, those results are promising for other simulations.

\subsubsection{Performance characterisation of the tested combisystem}

The same selected model has been used to characterise the performances of the tested system with the FSC method
(Fig. 16). So far, there is no more information about the system for comparison but the tests data. The characteristic curve of the tested system seems slightly above the performances estimated by the classic SCSPT method for the two tests. This is somehow in accordance with the performance overestimation observed in the Section 4.2.2. Anyway, Test 1 and Test 2 points are not that far from the estimated curve in comparison with the general scatter of the other points. The experimental application of the methodology offers a characterisation that seems realistic.

Other real combisystems with better-known performances (for example with several on-site data sets) should be modelled and characterised like this to further validate the methodology. However, this validation project would need a lot of time to find available systems, to collect and to analyse enough data for more complete comparisons.

\section{Conclusion and perspectives}

The improvement of the current SCSPT methodology is promising. While the former version of those tests evaluate with a good accuracy SCS performances for only one environment (climate and building) and only one system sizing, the "grey-box" model identification of the tested system extend the results to any environment and several sizes of collector. This extent let SCS be characterised only from a 12 days test on a semi-virtual test bench.

The model to be identified is made of two parts: a "White Box" part that gathers characteristics equations of the SCS main components; and a "Black Box" part using artificial neural networks that are taught how the system deals with external variables and its own states to meet the demands.

Comparison with numerical SCS models shows that the methodology is accurate. Identified models estimations of the energy consumed by the auxiliary boiler are closed to the detailed models ones. However, errors are getting larger when the environment become more extreme compared to

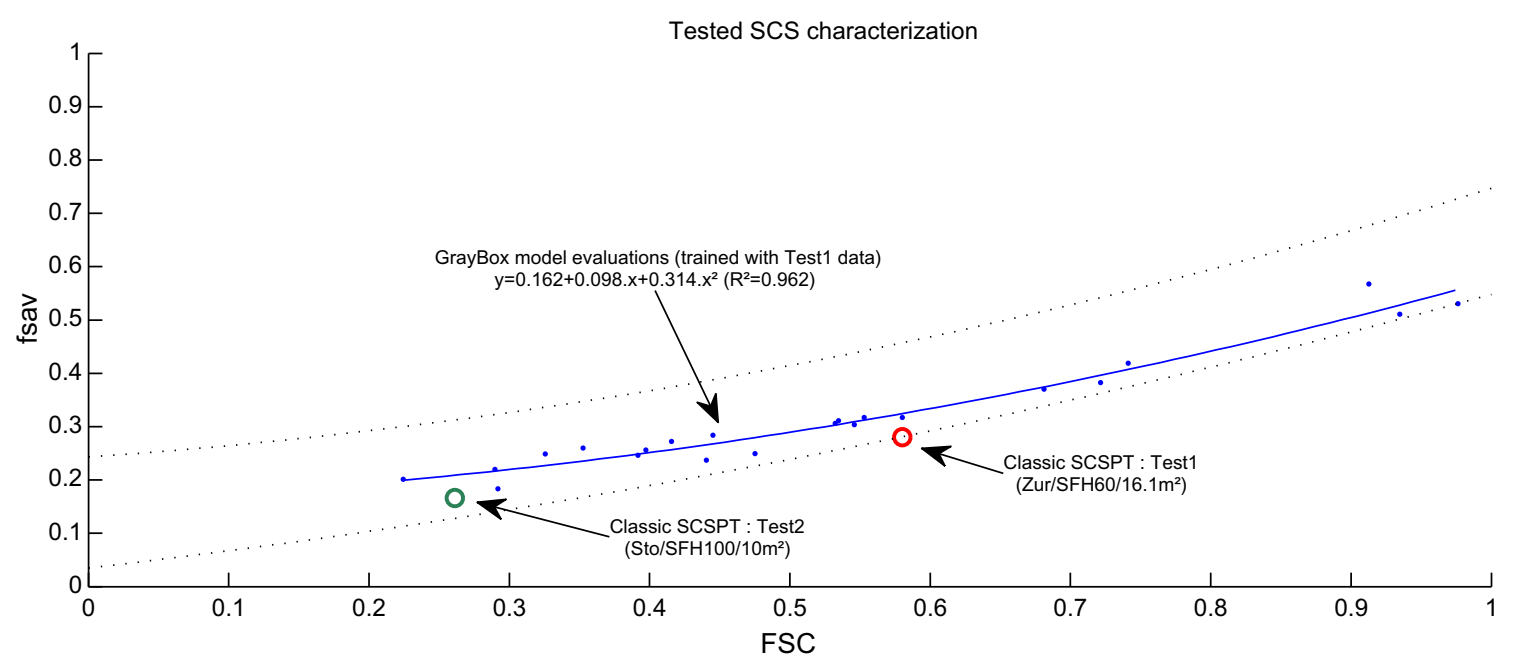

Fig. 16. Characterisation of the tested SCS. 
the training one. Some more work about the storage model may improve the accuracy of the model, especially for the collector output energy evaluation. Further studies must be done to check the validity range of estimations.

A real combisystem has been tested according to this methodology. The model trained from a test data set imitates well the SCS behaviour compared to a completely different experimental data set. Its characterisation seems to be in accordance with experimental results but need more information to be further validated. Some other real SCS will be tested soon on the INES semi-virtual test bench.

So far, the methodology is adapted for SCS using gas boiler as auxiliary energy and radiator as heat emitter. Some additional work must be done to find other models (like heating floor for instance) that suit the requirements of the "White Box" part of the model and so to have a methodology adapted for most of existing SCS. If the results still show good prediction performances, it would be interesting to consider this way as a standard test to improve the SCS market development.

\section{Acknowledgement}

This work has been supported by the French Agency for Environment and Energy Management (ADEME).

\section{References}

Albaric, M., Nowag, J., Papillon, P., 2008. Thermal performance evaluation of solar combisystems using a global approach. EUROSUN 2008, October 7-10, Lisbon, Portugal.

Albaric, M., Mette, B., Ullman, J., Drück, H., Papillon, P., 2010. Comparison of two different methods for solar combisystems performance testing. EUROSUN 2010, Graz, Austria.

ANSI/ASHRAE 93-86, 1986. Method of testing to determine the thermal performance of solar collectors. ASHRAE Inc., New-York.

Baccoli, R., Carlini, U., Mariotti, S., Innamorati, R., Solinas, E., Mura, P., 2010. Graybox and adaptative dynamic neural network identification models to infer the steady state efficiency of solar thermal collectors starting from the transient condition. Solar Energy 84, $1027-$ 1046.

Bales, C., 2002. Combitest - initial development of the AC/DC test method. Technical report. IEA Solar Heating \& Cooling Programme Task 26. <http://www.iea-shc.org/publications/task26/> accessed March 2011.

Dreyfus, G., Martinez, J.-M., Samuelides, M., Gordon, M.B., Badran, F., Thiria, S., Hérault, L., 2002. Réseaux de Neurones, Méthodologie et Applications, second ed. Eyrolles, Paris.

Drück, H., Bachmann, S., 2002. Performance testing of solar combisystems. Comparison of the CTSS with the ACDC Procedure. Technical Report. IEA Solar Heating \& Cooling Programme Task 26. <http:// www.iea-shc.org/publications/task26/> accessed March 2011.

European Standard EN 12975-2:2006, 2006. Thermal solar systems and components - solar collectors - Part 2: Test methods. CEN, Rue de Stassart, 36, B-1050, Brussels.

European Standard EN 442-2:1996, 1996. Radiators and convectors Part 2: Test methods and rating. CEN, Rue de Stassart, 36, B-1050, Brussels.

Heimrath, R., Haller, M., 2007. The reference heating system, the template solar system of Task 32. A report of IEA Solar Heating and Cooling programme - Task 32 "Advanced storage concepts for solar and low energy buildings". Report A2 of subtask A. <http:// www.iea-shc.org/publications/category.aspx?CategoryID $=62>$ accesed March 2011.

International Standar ISO 13790:2008(E), 2008. Energy performance of buildings - calculation of energy use for space heating and cooling.

Kalogirou, S.A., 2001. Artificial neural networks in renewable energy systems applications: a review. Renewable and Sustainable Energy Reviews 5, 373-401.

Klein, S.A. et al., 1994. TRNSYS, A Transient Simulation Program. Solar Energy Laboratory, University of Wisconsin.

Letz, T., 2006. Étude qualitative et quantitative du fonctionnement de Systèmes solaires combines en usage réel. Synthèse du programme de suivi sur sites. ADEME report. <http://www2.ademe.fr/servlet/getDoc?sort $=-1 \&$ cid $=96 \& \mathrm{~m}=3 \& \mathrm{id}=40819 \& \mathrm{ref}=\&$ nocache $=$ yes $\& \mathrm{p} 1=111>$ accessed March 2011.

Letz, T., Bales, C., Perers, B., 2009. A new concept for combisystems characterization: the FSC method. Solar Energy 83, 1540-1549.

Mackay, D.J.C., 1992. A practical Bayesian framework for backpropagation networks. Neural Computation 4, 448-472.

Marquardt, D.W., 1963. An algorithm for least-squares estimation of non-linear parameters. Journal of the Society of Industrial and, Applied Mathematics 11, 431-441.

Medinelli Sanino, L.A., Rojas Reischel, R.A., 2007. Modeling and identification of solar energy water heating system incorporating nonlinearities. Solar Energy 81, 570-580.

Mellit, A., Massi Pavan, A., 2010. A 24-h forecast of solar irradiance using artificial neural network: application for performance prediction of a grid-connected PV plant at Trieste, Italy. Solar Energy 84, 807-821.

Mette, B., Ullman, J., Drück, H., Albaric, M., Leconte, A., Papillon, P., 2010. Combisol project. Solar combisystem promotion and standardisation. D3.1: Comparison of test methods. $<$ http://www.combisol.eu/servlet $/$ KBaseShow?sort $=-1 \&$ cid $=21722 \& \mathrm{~m}=3 \&$ catid $=21753>$ accessed March 2011.

Nguyen, D., Widrow, B., 1990. Improving the learning speed of 2-layer neural networks by choosing initial values of the adaptative weights. Proceeding of the International Joint Conference on Neural Networks 3, 21-26.

Paoli, C., Voyant, C., Museli, M., Nivet, M.L., 2010. Forecasting of preprocessed daily solar radiation time series using neural networks. Solar Energy 84, 2146-2160.

Perers, B., 1997. An improved dynamic solar collector test method for determination of non-linear optical and thermal characteristics with multiple regression. Solar Energy 59, 163-178.

Perers, B., Bales, C., 2002. A solar collector model for TRNSYS simulation and system testing. Technical report. IEA Solar Heating \& Cooling Programme Task 26. <http://www.iea-shc.org/publications/task26/> accessed March 2011.

Réglementation Thermique RT2005, 2005. Méthode de calcul Th-CE.

Rumelhart, D.E., Hinton, G.E., Williams, R.J., 1986. Learning representations by back-propagating errors. Nature 323, 533-536.

Thür, A., Breider, J., Kuhness, G., 2010. Combisol project. Solar combisystem promotion and standardisation. D2.4: updated state of the art report if solar combisystems analysed within Combisol. $<$ http://www.combisol.eu/servlet/KBaseShow?sort=-1\&cid=21722\& $\mathrm{m}=3$ \&catid $=21757>$ accessed March 2011.

Thür, A., 2011. Combisol project. Solar Combisystems promotion and standardisation. D2.3: Guidelines for Design and Dimensioning. $<$ http://www.combisol.eu/servlet/KBaseShow?sort=-1\&cid=21763\&m= $3 \&$ catid $=21778>$ accessed March 2011.

Vogelsanger, P., 2002. The Concise Cycle Test method - A twelve day system test. Technical report. IEA Solar Heating \& Cooling Programme Task 26. <http://www.iea-shc.org/publications/task26/> accessed March 2011.

Widrow, B., Stearns, S., 1985. Adaptive Signal Processing. Prentice-Hall, Englewood Cliffs, NJ. 